\title{
RC0639: phase II study of paclitaxel, trastuzumab, and lapatinib as adjuvant therapy for early stage HER2-positive breast cancer
}

\author{
Alvaro Moreno-Aspitia • Amylou C. Dueck • Ismael Ghanem-Cañete • \\ Tejal Patel · Shaker Dakhil · David Johnson • Sandra Franco • Stephen Kahanic • \\ Gerardo Colon-Otero - Kathleen S. Tenner - Richard Rodeheffer • \\ Ann E. McCullough • Robert B. Jenkins • Frances M. Palmieri · Donald Northfelt • \\ Edith A. Perez
}

Received: 21 February 2013 / Accepted: 26 February 2013/Published online: 12 March 2013

(C) The Author(s) 2013. This article is published with open access at Springerlink.com

\begin{abstract}
Lapatinib adds to the efficacy of trastuzumab in preclinical models and also in the neo-adjuvant setting. This study assesses the safety and feasibility of adding lapatinib to paclitaxel and trastuzumab (THL) as part of the adjuvant therapy for HER2-positive breast cancer (HER2+ $\mathrm{BC})$. In this single-arm phase II study, patients with stages I-III HER2+ BC received standard anthracycline-based chemotherapy followed by weekly taxane, with concurrent standard trastuzumab, plus daily lapatinib for a total of 12 months. The primary endpoint was symptomatic congestive heart failure, secondary endpoints included overall safety. A total of 109 eligible patients were enrolled. Median follow-up is 4.3 years. No patients experienced congestive heart failure while on treatment. Mean left ventricular ejection fraction at baseline and at the end of THL were $63.6 \%(N=109, \mathrm{SD}=5.7)$ and $59.8 \%$ $(N=98, \mathrm{SD}=8.1)$, respectively [mean change $-3.95 \%$ $(N=98, \mathrm{SD}=8.3), p<0.001]$. One hundred and two
\end{abstract}

A. Moreno-Aspitia · G. Colon-Otero · E. A. Perez ( $\varangle)$

Division of Hematology and Oncology, Mayo Clinic, 4500 San

Pablo Rd. S., Jacksonville, FL 32224, USA

e-mail: perez.edith@mayo.edu

A. C. Dueck - A. E. McCullough - D. Northfelt

Mayo Clinic, 13400 E. Shea Blvd., Scottsdale, AZ 85259, USA

I. Ghanem-Cañete

Hospital Universitario 12 de Octubre, Avda de Córdoba s/n,

28041 Madrid, Spain

T. Patel

Methodist Cancer Center, 6445 Fannin, OPC-21, Houston, TX

77030, USA

S. Dakhil · D. Johnson

Cancer Center of Kansas, 818 N. Emporia St., Wichita, KS

67214, USA patients initiated post-AC treatment; of them, $31 \%$ experienced grade 3 (no G4) diarrhea with lapatinib at $750 \mathrm{mg} /$ day. The addition of lapatinib to paclitaxel and trastuzumab following AC does not add cardiac toxicity. Lapatinib dose of $750 \mathrm{mg}$ /day in combination with standard chemotherapy plus trastuzumab has acceptable overall tolerability.

Keywords Breast cancer - HER2 cardiac .

Gastrointestinal · Tolerability · Lapatinib · Adjuvant

\author{
Abbreviations \\ HER2 Human epidermal growth factor type 2 \\ HER2 + BC HER2-positive breast cancer \\ THL Paclitaxel, trastuzumab, and lapatinib \\ AC Cyclophosphamide \\ HL Trastuzumab and lapatinib \\ CHF Congestive heart failure \\ LVEF Left ventricular ejection fraction \\ G3 Grade 3 \\ S. Franco \\ Clinica del Country, Carrera 16 No. 82-57, Bogota, Columbia \\ S. Kahanic \\ Siouxland Hematology/Oncology, 230 Nebraska St., Sioux City, \\ IA 51101, USA \\ K. S. Tenner $\cdot$ R. Rodeheffer $\cdot$ R. B. Jenkins \\ Mayo Clinic, 200 First St. SW, Rochester, MN 55905, USA \\ F. M. Palmieri \\ Sarah Cannon Research Institute, 3322 West End Ave., \\ Nashville, TN 37203, USA
}




$\begin{array}{ll}\text { G4 } & \text { Grade } 4 \\ \text { DFS } & \text { Disease-free survival } \\ \text { OS } & \text { Overall survival } \\ \text { EGFR } & \text { Epidermal growth factor receptor } \\ \text { MBC } & \text { Metastatic breast cancer } \\ \text { ALTTO } & \begin{array}{l}\text { Adjuvant lapatinib and/or trastuzumab } \\ \text { treatment optimization }\end{array} \\ \text { NYHA } & \text { New York Heart Association } \\ \text { IHC } & \text { Immunohistochemistry } \\ \text { FISH } & \text { Fluorescence in situ hybridization } \\ \text { MUGA } & \text { Multiple-gated acquisition } \\ \text { ECHO } & \text { Echocardiogram } \\ \text { ECOG } & \text { Eastern cooperative oncology group } \\ \text { QOL } & \text { Quality of life } \\ \text { CTCAE } & \text { Common terminology criteria for adverse } \\ \text { events } & \text { Adverse event } \\ \text { ACE } & \text { Angiotensin converting enzyme } \\ \text { TH } & \text { Paclitaxel and trastuzumab } \\ \text { CAE } & \text { Cardiac adverse event } \\ \text { MI } & \text { Myocardial infarction } \\ \text { pCR } & \text { Pathological complete response }\end{array}$

\section{Introduction}

The human epidermal growth factor type 2 (HER2) is a trans-membrane receptor with intrinsic tyrosine kinase activity [1]. Approximately 15-20\% of invasive breast cancers are HER2 positive by gene amplification or protein overexpression [1-4]. The up-regulation of this pathway conveys an increased risk for disease relapse, disease progression, death [5], and an increased relative resistance to various anticancer therapies $[6,7]$.

Trastuzumab is a recombinant humanized monoclonal antibody against the extracellular domain of HER2 [8]. The addition of trastuzumab to adjuvant chemotherapy regimens of patients with early stage HER $2+$ BC leads to a significant improvement in disease-free survival (DFS) and overall survival (OS) as compared with chemotherapy alone [8-12]. However, despite the use of adjuvant trastuzumab plus chemotherapy $[8,13,14]$, there is still a risk of relapse of approximately $25 \%$ at 5 years. Thus, the search to improve the outcome of these patients continues [15].

Lapatinib is an oral dual HER1 (EGFR: epidermal growth factor receptor) and HER2 tyrosine kinase inhibitor targeting the intracellular domains of these receptors [16]. Lapatinib is currently approved by regulation agencies in different parts of the world for the treatment of HER2+ metastatic breast cancer (MBC) in combination with chemotherapy (capecitabine) or with endocrine therapy (letrozole) [17]. The different mechanisms of action of lapatinib and trastuzumab against the HER2 receptor lead to synergism of this combination in HER2 overexpressing breast cancer cells, in both the metastatic and the neoadjuvant settings [18-21]. Consequently, the combination of lapatinib and trastuzumab may lead to improved outcomes as adjuvant therapy for patients with early stage HER2+ BC. This combination strategy is currently being evaluated in the ALTTO (Adjuvant Lapatinib And/Or Trastuzumab Treatment Optimisation) trial [22, 23].

Cardiotoxicity is an uncommon, but important side effect of anti-HER2 therapy. Although the exact pathophysiologic mechanism is not fully understood, the mechanism appears more distinct than the one caused by the anthracyclines or other anticancer agents $[24,25]$. The four largest adjuvant trastuzumab-based trials (N9831, NSABP B-31, HERA, and BCIRG-006) have demonstrated an incidence of asymptomatic decrease in LVEF between 7.4 and $17.3 \%$, with an incidence of severe heart failure (New York Heart Association (NYHA) class III/IV) ranging from 0.6 to $4.1 \%$ [9-11]. Lapatinib-related cardiac events appear to occur at a much lower rate $(1.6 \%)$, even in patients previously treated with anthracyclines and trastuzumab [26]. The RC0639 study reported herein is a multicenter single-arm phase II clinical trial designed to assess the cardiac safety and feasibility of the addition of lapatinib to the standard adjuvant chemotherapy plus concurrent trastuzumab regimen similarly as provided on Arm C of the N9831 clinical trial $[8,10,15]$. Of note is that while we were conducting this pilot trial, there was another pilot study conducted by Dang et al. [27]. Our manuscript herein provides longer follow-up data and serves to put our results in the context of the data by Dang et al. [27] and the upcoming results of the large phase III ALTTO study.

\section{Patients and methods}

\section{Patient eligibility}

Eligible patients had centrally confirmed HER2-positive, surgically resected, invasive breast cancer. HER2 status was determined by an immunohistochemistry (IHC) score of 3+ (by Dako HercepTest FDA approved guideline) or by the presence of gene amplification as determined by fluorescence in situ hybridization (FISH) defined by a ratio of greater than or equal to 2.0. This was reviewed at two laboratories (Mayo Clinic, Rochester, MN and Scottsdale AZ). A LVEF greater than or equal to $50 \%$ measured by multiple-gated acquisition (MUGA) scan or echocardiogram (ECHO) within 14 days of study entry was mandatory. Other selected eligibility requirements included age (patients must be at least 18 years of age), Eastern Cooperative Oncology Group (ECOG) performance status less 
than or equal to two, and adequate hematologic, hepatic, and renal function. Patients with myocardial infarction within 6 months prior to registration, active angina pectoris, history of congestive heart failure (CHF), uncontrolled hypertension, or other clinically significant cardiac disease were ineligible. Patients with gastrointestinal problems that might interfere with the absorption of lapatinib were also excluded. An Institutional Review Board approval and patient informed consents were obtained from all patients.

\section{Study design and treatment}

The primary endpoint of this trial (RC0639) was cardiac safety, defined as the proportion of patients experiencing severe symptomatic CHF (NYHA Class III or IV with a drop in LVEF of at least 10 percentage points to below $50 \%$ as confirmed by a cardiologist). Secondary endpoints included overall safety profile, disease-free survival and overall survival, and selected quality of life (QOL) response by questionnaire. Tertiary endpoints included translational biomarkers.

The treatment schedule consisted of four cycles of doxorubicin (A: $60 \mathrm{mg} / \mathrm{m}^{2}$ day 1) and cyclophosphamide (C: $600 \mathrm{mg} / \mathrm{m}^{2}$ day 1) every 2 or 3 weeks, with or without the use of pegylated-G-CSF, followed by 12 weeks of THL: paclitaxel (T: $80 \mathrm{mg} / \mathrm{m}^{2}$ weekly), trastuzumab $(\mathrm{H}$ : $4 \mathrm{mg} / \mathrm{kg}$ loading dose on week one followed by $2 \mathrm{mg} / \mathrm{kg}$ weekly), and lapatinib (L: 1,000 mg PO daily), followed by 40 weeks of $\mathrm{HL}$ : trastuzumab $(6 \mathrm{mg} / \mathrm{kg}$ day 1 , every 3 weeks) and L: lapatinib (1,000 $\mathrm{mg}$ orally daily). The study was amended in July 2008, reducing the dose of L when given concurrently with $\mathrm{T}$ and $\mathrm{H}$ (from 1,000 to
$750 \mathrm{mg} /$ day) because of the high incidence of grade 3 and/ or $4(\mathrm{G} 3 / 4)$ diarrhea observed in the ongoing study.

Patients received radiation and adjuvant endocrine therapy according to standard treatment guidelines based on prior surgical approach, stage, and tumor characteristics.

\section{Toxicity evaluation}

The adverse effects were graded according to the National Cancer Institute Common Terminology Criteria for Adverse Events (CTCAE) version 3.0. Initiation of THL was not allowed in patients who developed significant cardiac events while receiving $\mathrm{AC}$, or in asymptomatic patients with a significant decrease in the LVEF (greater than or equal to $16 \%$ from baseline or less than or equal to $15 \%$ but with an LVEF less than $50 \%$ ), upon completion of AC. Evaluation of LVEF was done within 14 days before registration, at the end of Cycles 4,8 , and 12, and at 18 months, then again at $2,3,4$, and 5 years postrandomization.

\section{Treatment dose modifications}

Treatment dose modification algorithms were designed for the management of cardiac toxicity and diarrhea (Figs. 1, 2). $\mathrm{T}$ and $\mathrm{L}$ were permanently discontinued if the patient had a LVEF decrease of $10 \%$ or more plus a LVEF less than $40 \%$. If LVEF was between 40 and $49 \%$, we omitted the dose and re-evaluated LVEF in 3 weeks. If LVEF was less than or equal to $50 \%$ or between 45 and $49 \%$ with a decrease less than $10 \%$ of baseline, then the patient continued $\mathrm{T}$ (without dose modification) and $\mathrm{L}$ (with

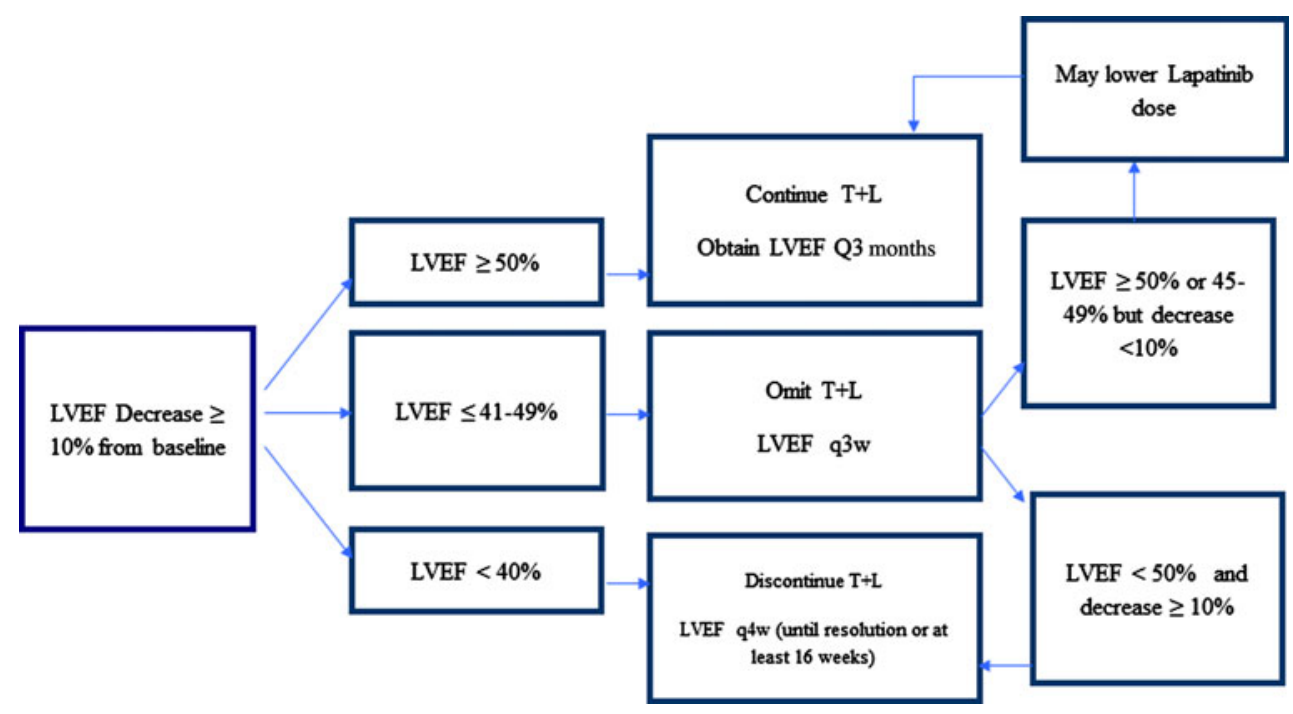

Fig. 1 Algorithm for the management of cardiac toxicity in RC0639 
consideration of dose reduction). If LVEF remained less than $50 \%$ and it represented a decrease of $10 \%$ or more from baseline value, $\mathrm{T}$ and $\mathrm{L}$ were stopped permanently.

One dose reduction in lapatinib (from 1,000 to $750 \mathrm{mg}$ / day during HL or from 750 to $500 \mathrm{mg}$ /day during THL after the mentioned amendment) was also permitted for other G3/4 lapatinib-related AE. Treatment could be delayed for at least 3 weeks to allow for resolution of the AE. If treatment had to be delayed for more than 3 weeks, then patients were taken off the study. In case of G3/4 confirmed interstitial pneumonitis, lapatinib was to be discontinued permanently. Management of treatment-related diarrhea is outlined in Fig. 2.

\section{Statistical considerations}

The primary endpoint of this trial was the proportion of patients experiencing CHF during the first 6 months of treatment. A true CHF rate of $3.5 \%$ or less was considered acceptable, and a true CHF rate of $10 \%$ or more would be unacceptably high. A two-stage design called for the treatment of 42 eligible patients in the first stage and a total of 101 eligible patients treated to test the null hypothesis that the true $\mathrm{CHF}$ rate in the given patient population was at most $3.5 \%$.

Statistical results presented herein primarily include descriptive statistics. Additionally, disease-free survival was defined as time from registration to first breast cancer recurrence, new primary cancer or death due to any cause. Overall survival was defined as time from registration to death due to any cause. Disease-free survival and overall survival were estimated using Kaplan-Meier. Post-baseline LVEF was compared to baseline using paired $t$ tests.

\section{Results}

Patient baseline characteristics

From April 2007 to October 2008, 122 patients were enrolled. Median follow-up was 4.3 years (range 0.1-5.2). Ten patients were deemed ineligible due to uncorroborated HER 2 positivity (by the central laboratory evaluation), one patient withdrew prior to treatment, one patient withdrew after beginning treatment, and one patient had a major treatment violation.

Characteristics of the remaining 109 patients are outlined in Table 1. The median age was 51.2 (28-72) years, and $53.2 \%$ were postmenopausal at the time of registration. Fifty-five percent of patients had node-positive disease, and $50.5 \%$ of patients had ER-/PR-negative tumors. Mastectomy and radiation therapy was performed in 65 patients $(59.6 \%)$. Most patients $(78.9 \%)$ received AC therapy in a dose-dense fashion.

Table 2 outlines reasons for ending active treatment. Twenty-three percent were due to treatment-related AEs,



Fig. 2 Algorithm for the management of diarrhea in RC0639 
Table 1 Patient baseline characteristics $(N=109)$

\begin{tabular}{|c|c|c|}
\hline Characteristic & No. of patients & $\%$ \\
\hline Median age, years (range) & 51 (Range 28-72) & \\
\hline \multicolumn{3}{|l|}{ Race } \\
\hline White & 94 & 86.2 \\
\hline Black or African-American & 12 & 11 \\
\hline Asian & 2 & 1.8 \\
\hline American Indian or Alaska native & 1 & 0.9 \\
\hline \multicolumn{3}{|l|}{ ECOG performance status } \\
\hline 0 & 91 & 83.5 \\
\hline 1 & 18 & 16.5 \\
\hline \multicolumn{3}{|l|}{ T Stage } \\
\hline 1 & 43 & 39.4 \\
\hline 2 & 58 & 53.2 \\
\hline 3 & 6 & 5.5 \\
\hline Missing & 2 & 1.8 \\
\hline \multicolumn{3}{|l|}{ Nodal status } \\
\hline N0 & 49 & 45 \\
\hline N1 & 32 & 29.4 \\
\hline $\mathrm{N} 2$ & 12 & 11 \\
\hline N3 & 14 & 12.8 \\
\hline SLN+ without full axillary dissection & 2 & 1.8 \\
\hline \multicolumn{3}{|l|}{ Hormonal status } \\
\hline ER and/or PR positive & 54 & 49.5 \\
\hline ER and PR negative & 55 & 50.5 \\
\hline \multicolumn{3}{|l|}{ HER2 status } \\
\hline Positive & 109 & 100 \\
\hline FISH Amp/IHC Pos & 93 & 85.3 \\
\hline FISH Amp/IHC Neg & 8 & 7.3 \\
\hline FISH Not Amp/IHC Pos & 6 & 5.5 \\
\hline FISH not done/IHC Pos & 2 & 1.8 \\
\hline Median LVEF \% (range) & 63.3 (Range 52-78) & \\
\hline \multicolumn{3}{|l|}{ Smoking status } \\
\hline Never & 60 & 55 \\
\hline Former & 24 & 22 \\
\hline Data not available & 25 & 22.9 \\
\hline \multicolumn{3}{|l|}{ Current use of hypertensive medication } \\
\hline Yes & 28 & 25.7 \\
\hline No & 81 & 74.3 \\
\hline \multicolumn{3}{|l|}{ History of diabetes } \\
\hline Yes & 10 & 9.2 \\
\hline No & 99 & 90.8 \\
\hline \multicolumn{3}{|l|}{ Menopausal status } \\
\hline Premenopausal & 43 & 39.4 \\
\hline Perimenopausal & 8 & 7.3 \\
\hline Postmenopausal & 58 & 53.2 \\
\hline
\end{tabular}

ECOG PS Eastern Cooperative Oncology Group performance status

mainly before the protocol amendment in May 2008 due to the higher than expected incidence of G3/4 diarrhea in the first 68 eligible patients treated with THL.
Table 2 Reasons for ending active treatment

\begin{tabular}{lc}
\hline Completed study per protocol & $55(50.5 \%)$ \\
Refused further treatment & $20(18.3 \%)$ \\
- Unacceptable side effects & $9(8.3 \%)$ \\
- Reason not given & $7(6.4 \%)$ \\
- Non-compliant & $2(1.8 \%)$ \\
- Patient choice & $2(1.8 \%)$ \\
Adverse event & $25(22.9 \%)$ \\
Disease progression & $1(0.9 \%)$ \\
Alternate treatment & $1(0.9 \%)$ \\
Other medical problems & $2(1.8 \%)$ \\
Other & $5(4.6 \%)$ \\
\hline
\end{tabular}

Cardiac safety and cardiac events

No patients experienced CHF or cardiac death while on active treatment. However, there was one patient with confirmed CHF, and one patient who may have died due to myocardial infarction (MI) after they went off the study treatment. The patient with CHF experienced grade 1 left ventricular systolic dysfunction in Cycle 4 and G1 diastolic dysfunction in Cycles 4 and 6 and refused further treatment after completing 2 cycles of THL. Clinically symptomatic CHF occurred 1.8 months post-THL discontinuation with an LVEF of $45 \%$ and dyspnea on exertion. The patient received an angiotensin converting enzyme (ACE) inhibitor, a beta blocker and a diuretic for ongoing management of CHF for the next 2 years. One year after the confirmed CHF episode, this patient was reported to be asymptomatic with an LVEF of $59 \%$. Two years after the confirmed CHF event, the patient's LVEF was $60 \%$ and the patient was reported to be asymptomatic and taking no medications.

The other patient who sustained a cardiac event went off study treatment due to G3 diarrhea and died suddenly 2.9 months post-discontinuation of therapy. It was presumed by the local physician that the event was related to a massive MI, although an autopsy was not performed. Because in these two patients the cardiac events occurred up to 3 months after coming off study, it seems warranted to continue monitoring cardiac symptoms for a few months upon discontinuation of dual anti-HER2 therapy.

Five patients $(4.6 \%)$ had other G3/4 cardiac adverse events (CAEs) during active treatment, three $(2.8 \%)$ presented with G3 left ventricular dysfunction, and two $(1.8 \%)$ with G4 thrombosis. Regarding the three patients with G3 left ventricular failure, one patient's reported that LVEF remained less than $50 \%$ for 12 months and recovered after 18 months with three LVEF reports of over $50 \%$ each 1 year apart. Another patient had continued LVEF reports less than $50 \% 2$ years after discontinuing treatment, and the other patient recovered to have an LVEF 
over $50 \% 3$ months after discontinuing treatment, but had the LVEF drop to less than $50 \% 8$ months later. Table 3 summarizes all CAEs.

\section{Serial evaluation of LVEF}

Table 4 shows mean and median values and ranges of LVEF for each evaluation point and the absolute LVEF changes from baseline evaluation. Statistically significant decreases from baseline in the LVEF were observed at the Cycle 8, Cycle 12, 18 months and 5-year evaluation points. Despite the statistical significance at some evaluation points, the mean changes were less than $5 \%$ from baseline and therefore not clinically significant in most cases.

Adverse event profile

Considering all AEs from Cycle 1 and later, the most common AEs were fatigue (94\%), diarrhea (91\%),

Table 3 All cardiac adverse events

\begin{tabular}{lcc}
\hline Cardiac adverse event & All treatment & Post-AC \\
\hline G1 left ventricular failure & $45(41.3 \%)$ & $41(40.2 \%)$ \\
G2 left ventricular failure & $10(9.2 \%)$ & $9(8.8 \%)$ \\
G3 left ventricular failure & $3(2.8 \%)$ & $3(2.9 \%)$ \\
G1 diastolic dysfunction & $10(9.2 \%)$ & $10(9.8 \%)$ \\
G2 diastolic dysfunction & $1(0.9 \%)$ & $1(1.0 \%)$ \\
G2 hypotension & $1(0.9 \%)$ & $1(1.0 \%)$ \\
G4 thrombosis & $2(1.8 \%)$ & $2(1.8 \%)$ \\
\hline
\end{tabular}

All treatment: $N=109$; Post-AC: $N=102$

CTCAE v3.0: left ventricular failure $\mathrm{G} 1=<60-50 \%$, $\mathrm{G} 2=<50-40 \%, \mathrm{G} 3=<40-20 \%$ and symptomatic CHF responsive to intervention; Diastolic dysfunction: G1 = Asymptomatic, intervention not indicated, G2 = Asymptomatic, intervention indicated neuropathy-sensory effects $(70 \%)$, acneiform rash $(61 \%)$, myalgia (59\%), arthralgias (61\%), bone pain $(54 \%)$, and decrease in LVEF (53 \%; G1/2: $50 \%$ ). Diarrhea was, by far, the most common G3/4 AE (38\%). Due to the high incidence of diarrhea G3/4 during the early accrual, the study was amended reducing the dose of lapatinib when given concurrently with paclitaxel (dose reduced from 1,000 to $750 \mathrm{mg} /$ day for Cycles 5-8, that is, THL; $1,000 \mathrm{mg} /$ day dosing was resumed after treatment with paclitaxel had ended). This dose reduction, along with a more aggressive and early treatment of the diarrhea, as outlined in Fig. 2, allowed for an improvement in the incidence of G3/4 diarrhea events, which led to an increased number of patients being able to receive lapatinib concomitantly with trastuzumab and paclitaxel during Cycles 5-8. Among patients initiating THL at the 1,000 mg/day lapatinib dose, G3 diarrhea following THL initiation was $41 \%(30 / 73)$ and G4 $2.7 \%(2 / 73)$; and at the $750 \mathrm{mg}$ /day lapatinib dose, G3 was $31 \%$ (9/29) and no G4 was reported. Mild liver transaminitis were common (22 and $23 \% \mathrm{G} 1 / 2$ increase in AST/ALT, respectively), but severe abnormalities of these liver enzymes were rare (G3/ $4<3 \%$ ). Leukopenia/neutropenia were the most common hematologic AEs (G3/4 occurring with a frequency of 22.9 and $27.5 \%$, respectively). Table 5 summarizes all the AEs occurring with an incidence of $20 \%$ or more.

Disease-free survival and overall survival

Five patients experienced disease recurrence, and one patient developed a new primary cancer. At last follow-up, five patients had died (four due to breast cancer and one due to suspected MI). Disease-free survival at 3 years was estimated to be $92.9 \%$ (95\% CI 85.6-96.5). Overall survival at 3 years was estimated to be $95.0 \%(95 \%$ CI 88.4-97.9).

Table 4 LVEF for each evaluation point

\begin{tabular}{|c|c|c|c|c|c|c|c|c|c|c|}
\hline \multirow[t]{2}{*}{ Visit } & \multirow[t]{2}{*}{$N$} & \multirow[t]{2}{*}{ Mean $(\%)$} & \multirow[t]{2}{*}{$\mathrm{SD}(\%)$} & \multirow[t]{2}{*}{ Median (\%) } & \multirow[t]{2}{*}{ Range $(\%)$} & \multicolumn{5}{|c|}{ LVEF absolute changes from baseline } \\
\hline & & & & & & Mean $(\%)$ & $\mathrm{SD}(\%)$ & $p^{*}$ & Median (\%) & Range $(\%)$ \\
\hline Baseline & 109 & 63.6 & 5.7 & 63.3 & $52-78$ & & & & & \\
\hline End cycle 4 & 105 & 63.3 & 6.4 & 63 & $48.5-78$ & -0.58 & 5.6 & 0.29 & 0 & $-15-16$ \\
\hline Cycle 8 & 98 & 59.8 & 8.1 & 60 & $20-77$ & -3.95 & 8.3 & $<0.001$ & -2.6 & $-32-22$ \\
\hline Cycle 12 & 95 & 59.3 & 7.1 & 60 & $41-79$ & -4.45 & 7.2 & $<0.001$ & -5 & $-26-13$ \\
\hline 18 Months & 87 & 60.1 & 6.8 & 60 & $45-86$ & -3.51 & 6.9 & $<0.001$ & -4.5 & $-16.4-15$ \\
\hline 2 Years & 71 & 62.1 & 7.4 & 62 & $43-84$ & -1.67 & 7.6 & 0.07 & -1.2 & $-24.7-14.2$ \\
\hline 3 Years & 61 & 61.5 & 7.4 & 61 & $30-80$ & -2.05 & 8.5 & 0.06 & -2 & $-32.1-15$ \\
\hline 4 Years & 51 & 61.6 & 6.6 & 62 & $35-75$ & -2.01 & 7.7 & 0.07 & -1 & $-20-15$ \\
\hline 5 Years & 20 & 57.7 & 6.9 & 58.1 & $40-68$ & -4.83 & 9.2 & 0.03 & -3.5 & $-30-12$ \\
\hline
\end{tabular}

$S D$ standard deviation

* Paired $t$ test $p$ value 
Table 5 Adverse events occurring with an incidence of $20 \%$ or more

\begin{tabular}{lccc}
\hline Adverse event & Grade $1-2$ & Grade 3 & Grade 4 \\
\hline Fatigue & $87(79.9 \%)$ & $14(12.8 \%)$ & $1(0.9 \%)$ \\
Diarrhea & $58(53.2 \%)$ & $39(35.8 \%)$ & $2(1.8 \%)$ \\
Neuro-sensory & $71(65.1 \%)$ & $5(4.6 \%)$ & $0(0 \%)$ \\
Acne & $61(55.9 \%)$ & $5(4.6 \%)$ & $0(0 \%)$ \\
Myalgia & $61(55.9 \%)$ & $3(2.8 \%)$ & $0(0 \%)$ \\
Arthralgia & $64(58.7 \%)$ & $2(1.8 \%)$ & $0(0 \%)$ \\
Pain-bone & $53(48.6 \%)$ & $6(4.6 \%)$ & $0(0 \%)$ \\
Decrease LVEF & $55(50.5 \%)$ & $3(2.8 \%)$ & $0(0 \%)$ \\
Dyspnea & $44(40.7 \%)$ & $3(2.8 \%)$ & $1(0.9 \%)$ \\
Neutropenia & $7(6.4 \%)$ & $8(7.3 \%)$ & $22(20.2 \%)$ \\
Alopecia & $36(33 \%)$ & $0(0 \%)$ & $0(0 \%)$ \\
Anemia & $30(27.5 \%)$ & $4(3.7 \%)$ & $0(0 \%)$ \\
Nausea & $27(24.8 \%)$ & $7(6.4 \%)$ & $0(0 \%)$ \\
Leukopenia & $8(7.3 \%)$ & $12(11 \%)$ & $13(11.9 \%)$ \\
ALT & $25(22.9 \%)$ & $3(2.8 \%)$ & $0(0 \%)$ \\
AST & $24(22.0 \%)$ & $2(1.8 \%)$ & $0(0 \%)$ \\
\hline$N$
\end{tabular}

$N=109$, includes all cycles of treatment, including AC chemotherapy

\section{Discussion}

Despite the significant benefit of the addition of trastuzumab for the adjuvant treatment of HER2 + BC, up to one out of every four patients still relapses at 5 years [812]. The current data of the activity of single agent lapatinib in combination with chemotherapy in the adjuvant or neo-adjuvant setting of patients with early stage HER2+ $\mathrm{BC}$ seem to be no better and in some trials even inferior to trastuzumab and chemotherapy [28]. Additionally, the HER2 + subset of patients $(n=620)$ in the German neoadjuvant phase III GeparQuinto trial, who received four cycles of epirubicin and cyclophosphamide followed by four cycles of docetaxel along with standard dose of trastuzumab $(n=307)$ or lapatinib $(\mathrm{n}=308)$ at $1,000 \mathrm{mg} /$ daily during the entire length of the chemotherapy regimen (24 weeks), were also noted to achieve a lower pathological complete response (pCR) with lapatinib $(22.7 \%)$ than with trastuzumab (30.3\%; $p=0.04)$ [29]. However, several sources of preclinical and clinical data suggest that combined anti-HER2 approaches may be optimal for efficacy. The dual HER2 blockade seems to significantly improve the pCR rate of patients receiving this combination in the neo-adjuvant setting, and achieving a pCR in patients with HER2 + disease is associated with improved long-term outcome [21, 29]. The neo-adjuvant neo-ALTTO trial randomized 455 patients who received either lapatinib or trastuzumab, or lapatinib with trastuzumab for a total of 6 weeks. Patients then continued on the same targeted therapy plus weekly paclitaxel for a further 12 weeks until surgery. This demonstrated that the combination led to a
$51.3 \%$ pCR rate compared with either trastuzumab or lapatinib alone ( $29.5 \%$ vs. $24.7 \%$, respectively; $p<0.01$ for both) [19], corroborating that dual blockade is more effective than a single anti-HER2 agent alone.

Our study evaluated the cardiac safety of the addition of lapatinib to the standard chemotherapy plus trastuzumab regimen provided in arm $\mathrm{C}$ of the $\mathrm{N} 9831$ pivotal trial $[8$, 10]. The 3-year cumulative incidence of cardiac events (AE or cardiac deaths) observed in the N9831 adjuvant treatment regimen was $3.3 \%$ [26]. In the current RC0639 clinical trial, no cases of symptomatic CHF were noted during on-study treatment and only $3 \%$ of the patients were classified as having grade 3 decrease in LVEF (EF $20-40 \%$ ). The incidence of CHF noted in this trial is actually numerically lower than that reported in a smaller phase II trial of dose-dense AC therapy followed by THL reported by Dang et al. [27]. In the Dang et al. trial, the chemotherapy and trastuzumab doses were similar to our study, and lapatinib was given at $1,000 \mathrm{mg}$ orally daily, for up to 12 months along with trastuzumab. Median followup was 22 months (range 18-31 months). Three out of 95 patients $(3 \%)$ in this study developed congestive heart failure, and three patients dropped out because of significant asymptomatic LVEF decline during THL followed by HL. An additional three patients had a significant asymptomatic LVEF decline but were subsequently able to resume anti-HER2 therapy. The conclusion of the authors was that this combination was not feasible, not because of excessive cardiotoxicity, but due to excessive problems with diarrhea $(70 \%$ of patients had diarrhea within the first cycle of treatment, and the overall incidence of grade 3 diarrhea on the patients who received THL therapy was $29 \%$ ). Overall, $43 \%$ of patients had a lapatinib dose reduction, mostly because of grade 3 or unacceptable grade 2 or less diarrhea despite active management.

One of the limitations of our present study is that only $50.5 \%$ of patients enrolled completed the entire treatment as specified in the protocol, which could limit the evaluation of cardiac toxicity. The main reasons for the high dropout rate were patient refusal or intolerable AEs, particularly diarrhea, as also noted by Dang et al. However, the subsequent dose modification of lapatinib and early, aggressive management of the diarrhea alleviated symptoms and allowed more patients to adhere to the on-protocol treatment. Similar findings were encountered in a 3-cohort phase I trial of 63 patients receiving the combination of THL. When lapatinib was prescribed at $1,000 \mathrm{mg} / \mathrm{day}$, the most frequently reported AEs for all cohorts was diarrhea ( $83 \%)$, but this AE was significantly improved with the reduction in the lapatinib dose to $750 \mathrm{mg} /$ day and early institution of loperamide (grade 3 diarrhea improved from 62 to $20 \%$ ) [30].

Diarrhea seems to be a frequent and challenging toxicity in regimens using the combination of lapatinib-paclitaxel 
[31] and may be related to increased systemic exposure of these drugs when given concurrently [31, 32].

The experience gained in this pilot study as well as in the subsequent NCCTG N083E pilot study (adjuvant docetaxel, carboplatin, trastuzumab, and lapatinib; TCHL) was extremely helpful in defining the management algorithm for Arm D of the large phase III adjuvant ALTTO trial (chemotherapy plus trastuzumab plus lapatinib as given in these 2 pilot trials-RC0639 and N083E). These data helped with the decision to use a starting dose of $750 \mathrm{mg} /$ day of lapatinib during the combination of a taxane and the dual HER2 blockade as well as helped to better define the need for aggressive intervention for the management of diarrhea. Another important observation of our study is that the lapatinib dose can be further reduced to $500 \mathrm{mg} /$ day during THL and increased to $1,000 \mathrm{mg} /$ day during the HL phase depending on tolerability.

\section{Conclusion}

In conclusion, our data suggest that lapatinib given concurrently with paclitaxel and trastuzumab does not add toxicity to the cardiac safety profile of the standard AC-TH regimen, that the dose of lapatinib with concurrent taxane and trastuzumab should not exceed $750 \mathrm{mg}$ daily, that diarrhea is the most common serious AE of this regimen and early aggressive management of it is absolutely necessary, and that monitoring of cardiac symptoms for a few months upon discontinuation of dual anti-HER2 therapy is warranted.

Acknowledgments Palmieri F, Dueck A, Johnson B, et al. Cardiac Safety of Lapatinib Given Concurrently with Paclitaxel and Trastuzumab as Part of Adjuvant Therapy for Patients with HER2+ Breast Cancer: Pilot Data from the Mayo Clinic Cancer Research Consortium Trial RC0639. Cancer Res 2009; 69(24 Suppl):3086. Preliminary reports from this study were presented at the Thirty-Second Annual CTRC-AACR San Antonio Breast Cancer Symposium Dec 10-13, 2009; San Antonio, TX (abstract 3086). Study conduct was partially funded by Mayo Clinic and GlaxoSmithKline, Inc (GSK). GSK did not contribute to the drafting or completion of this manuscript.

Conflict of interest Edith Perez disclosed that Mayo Clinic received research funding from GlaxoSmithKline and Genentech. All other authors declare that they have no competing interests.

Open Access This article is distributed under the terms of the Creative Commons Attribution Noncommercial License which permits any noncommercial use, distribution, and reproduction in any medium, provided the original author(s) and the source are credited.

\section{References}

1. Perez EA, Roche PC, Jenkins RB, Reynolds CA, Halling KC, Ingle JN, Wold LE (2002) HER2 testing in patients with breast cancer: poor correlation between weak positivity by immunohistochemistry and gene amplification by fluorescence in situ hybridization. Mayo Clin Proc 77(2):148-154

2. Coussens L, Yang-Feng TL, Liao YC, Chen E, Gray A, McGrath J, Seeburg PH, Libermann TA, Schlessinger J, Francke U et al (1985) Tyrosine kinase receptor with extensive homology to EGF receptor shares chromosomal location with neu oncogene. Science 230(4730):1132-1139

3. Ross JR (2009) Breast cancer biomarkers and HER2 testing after 10 years of ani-HER2 therapy. Drug News perspect 22(2):93-106

4. Yaziji H, Goldstein LC, Barry TS, Werling R, Hwang H, Ellis GK, Gralow JR, Livingston RB, Gown AM (2004) HER-2 testing in breast cancer using parallel tissue-based methods. JAMA 291(16):1972-1977

5. Slamon DJ, Clark GM, Wong SG, Levin WJ, Ullrich A, McGuire WL (1987) Human breast cancer: correlation of relapse and survival with amplification of the HER-2/neu oncogene. Science 235(4785): $177-182$

6. Wright C, Nicholson S, Angus B, Sainsbury JR, Farndon J, Cairns J, Harris AL, Horne CH (1992) Relationship between c-erbB-2 protein product expression and response to endocrine therapy in advanced breast cancer. Br J Cancer 65(1):118-121

7. Benz CC, Scott GK, Sarup JC, Johnson RM, Tripathy D, Coronado E, Shepard HM, Osborne CK (1992) Estrogen-dependent, tamoxifen-resistant tumorigenic growth of MCF-7 cells transfected with HER2/neu. Breast Cancer Res Treat 24(2):85-95

8. Perez EA, Romond EH, Suman VJ, Jeong JH, Davidson NE, Geyer CE Jr, Martino S, Mamounas EP, Kaufman PA, Wolmark N (2011) Four-year follow-up of trastuzumab plus adjuvant chemotherapy for operable human epidermal growth factor receptor 2-positive breast cancer: joint analysis of data from NCCTG N9831 and NSABP B-31. J Clin Oncol 29(25):3366-3373

9. Slamon D, Eiermann W, Robert N, Pienkowski T, Martin M, Press M, Mackey J, Glaspy J, Chan A, Pawlicki M et al (2011) Adjuvant trastuzumab in HER2-positive breast cancer. N Engl J Med 365(14):1273-1283

10. Romond EH, Perez EA, Bryant J, Suman VJ, Geyer CE Jr, Davidson NE, Tan-Chiu E, Martino S, Paik S, Kaufman PA et al (2005) Trastuzumab plus adjuvant chemotherapy for operable HER2-positive breast cancer. N Engl J Med 353(16):1673-1684

11. Piccart-Gebhart MJ, Procter M, Leyland-Jones B, Goldhirsch A, Untch M, Smith I, Gianni L, Baselga J, Bell R, Jackisch C et al (2005) Trastuzumab after adjuvant chemotherapy in HER2positive breast cancer. N Engl J Med 353(16):1659-1672

12. Joensuu H, Kellokumpu-Lehtinen PL, Bono P, Alanko T, Kataja V, Asola R, Utriainen T, Kokko R, Hemminki A, Tarkkanen M et al (2006) Adjuvant docetaxel or vinorelbine with or without trastuzumab for breast cancer. N Engl J Med 354(8):809-820

13. Winstanley J, Cooke T, Murray GD, Platt-Higgins A, George WD, Holt S, Myskov M, Spedding A, Barraclough BR, Rudland PS (1991) The long term prognostic significance of c-erbB-2 in primary breast cancer. Br J Cancer 63(3):447-450

14. Ross JS, Fletcher JA (1998) The HER-2/neu oncogene in breast cancer: prognostic factor, predictive factor, and target for therapy. Oncologist 3(4):237-252

15. Perez EA, Suman VJ, Davidson NE, Gralow JR, Kaufman PA, Visscher DW, Chen B, Ingle JN, Dakhil SR, Zujewski J et al (2011) Sequential versus concurrent trastuzumab in adjuvant chemotherapy for breast cancer. J Clin Oncol 29(34):4491-4497

16. Xia W, Mullin RJ, Keith BR, Liu LH, Ma H, Rusnak DW, Owens G, Alligood KJ, Spector NL (2002) Anti-tumor activity of GW572016: a dual tyrosine kinase inhibitor blocks EGF activation of EGFR/erbB2 and downstream Erk1/2 and AKT pathways. Oncogene 21(41):6255-6263

17. Johnston S, Pippen J Jr, Pivot X, Lichinitser M, Sadeghi S, Dieras V, Gomez HL, Romieu G, Manikhas A, Kennedy MJ et al (2009) 
Lapatinib combined with letrozole versus letrozole and placebo as first-line therapy for postmenopausal hormone receptor-positive metastatic breast cancer. J Clin Oncol 27(33):5538-5546

18. Konecny GE, Pegram MD, Venkatesan N, Finn R, Yang G, Rahmeh M, Untch M, Rusnak DW, Spehar G, Mullin RJ et al (2006) Activity of the dual kinase inhibitor lapatinib (GW572016) against HER-2-overexpressing and trastuzumabtreated breast cancer cells. Cancer Res 66(3):1630-1639

19. Baselga J, Bradbury I, Eidtmann H, Di Cosimo S, de Azambuja E, Aura C, Gomez H, Dinh P, Fauria K, Van Dooren V et al (2012) Lapatinib with trastuzumab for HER2-positive early breast cancer (NeoALTTO): a randomised, open-label, multicentre, phase 3 trial. Lancet 379(9816):633-640

20. Storniolo AM, Pegram MD, Overmoyer B, Silverman P, Peacock NW, Jones SF, Loftiss J, Arya N, Koch KM, Paul E et al (2008) Phase I dose escalation and pharmacokinetic study of lapatinib in combination with trastuzumab in patients with advanced ErbB2positive breast cancer. J Clin Oncol 26(20):3317-3323

21. Blackwell KL, Burstein HJ, Storniolo AM, Rugo H, Sledge G, Koehler M, Ellis C, Casey M, Vukelja S, Bischoff J et al (2010) Randomized study of Lapatinib alone or in combination with trastuzumab in women with ErbB2-positive, trastuzumab-refractory metastatic breast cancer. J Clin Oncol 28(7):1124-1130

22. ClinicalTrials.gov G, Group, NCCT, (NCI); NCI, Group; BI, Group NCT ALTTO (Adjuvant Lapatinib And/Or Trastuzumab Treatment Optimisation) Study; BIG 2-06/N063D. NCT00490139 06/20/2007 http://clinicaltrials.gov/ct2/show/ NCT00490139. Accessed 04/02/2012

23. ALTTO (Adjuvant Lapatinib And/Or Trastuzumab Treatment Optimisation) Study; BIG 2-06/N063D http://clinicaltrials.gov/ ct2/show/NCT00490139

24. Ewer MS, Vooletich MT, Durand JB, Woods ML, Davis JR, Valero V, Lenihan DJ (2005) Reversibility of trastuzumab-related cardiotoxicity: new insights based on clinical course and response to medical treatment. J Clin Oncol 23(31):7820-7826

25. Levine MN (2005) Trastuzumab cardiac side effects: only time will tell. J Clin Oncol 23(31):7775-7776
26. Perez EA, Suman VJ, Davidson NE, Sledge GW, Kaufman PA, Hudis CA, Martino S, Gralow JR, Dakhil SR, Ingle JN et al (2008) Cardiac safety analysis of doxorubicin and cyclophosphamide followed by paclitaxel with or without trastuzumab in the North Central Cancer Treatment Group N9831 adjuvant breast cancer trial. J Clin Oncol 26(8):1231-1238

27. Dang C, Lin N, Moy B, Come S, Sugarman S, Morris P, Abbruzzi A, Chen C, Steingart R, Patil S et al (2010) Dose-dense doxorubicin and cyclophosphamide followed by weekly paclitaxel with trastuzumab and lapatinib in HER2/neu-overexpressed/ amplified breast cancer is not feasible because of excessive diarrhea. J Clin Oncol 28(18):2982-2988

28. GlaxoSmithKline (2012) Lapatinib clinical trial update. 2011. http://wwwgskcom/media/pressreleases/2011/2011-pressrelease$614837 \mathrm{htm}$

29. Untch M, Loibl S, Bischoff J, Eidtmann H, Kaufmann M, Blohmer JU, Hilfrich J, Strumberg D, Fasching PA, Kreienberg R et al (2012) Lapatinib versus trastuzumab in combination with neoadjuvant anthracycline-taxane-based chemotherapy (GeparQuinto, GBG 44): a randomised phase 3 trial. Lancet Oncol 13(2):135-144

30. Esteva FJ, Hagan MK, Brewster A, Williams W, Florance AM, Koch K, Turner SJ, Ridderheim M, Perez AT (2010) Updated efficacy and safety assessment of first-line therapy with lapatinib, trastuzumab, and paclitaxel in HER2 + metastatic breast cancer. J Clin Oncol 28(15_suppl):1046

31. Di Leo A, Gomez HL, Aziz Z, Zvirbule Z, Bines J, Arbushites MC, Guerrera SF, Koehler M, Oliva C, Stein SH et al (2008) Phase III, double-blind, randomized study comparing lapatinib plus paclitaxel with placebo plus paclitaxel as first-line treatment for metastatic breast cancer. J Clin Oncol 26(34):5544-5552

32. Crown J, Burris H III, Jones S, Koch K, Fittipaldo A, Parikh R, Koehler M (2007) Safety and tolerability of lapatinib in combination with taxanes (T) in patients with breast cancer (BC). J Clin Oncol 25(18_suppl):1027 